\title{
AN INTRODUCTION TO, AND DISCUSSION OF, THE IMPLEMENTATION OF THE ADVANCED AMALGAMATED AGILE MANUFACTURING SYSTEM
}

\author{
R. Mclean ${ }^{1} \&$ G. Bright ${ }^{1}$
}

\section{ARTICLE INFO}

\section{Article details}

Submitted by authors 29 Aug 2018 Accepted for publication 17 Sept 2018 Available online $\quad 10 \mathrm{Dec} 2018$

\section{Contact details}

* Corresponding author roscoemclean@gmail.com

Author affiliations

1 University of KwaZulu-Natal, South Africa

DOI

http://dx.doi.org/10.7166/29-4-1618

\section{ABSTRACT}

The paradigm of reconfigurable manufacturing systems (RMSs) is still relatively new in implementation, even though research into the subject has been ongoing for over 15 years. Many supporting technologies are needed to make RMSs feasible, including the addition of flexible fixturing. This paper investigates and discusses the effect of adding flexible fixturing to the reconfigurable paradigm, and proposes solutions to problems that are inherent in RMSs and in the addition of flexible fixturing.

\section{OPSOMMING}

Die paradigma van herkonfigureerbare vervaardigingstelsels (HVS) is nog relatief nuut in implementering, selfs al is navorsing hieroor vir meer as 15 jaar aan die gang. Baie ondersteunende tegnologieë is nodig om die HVS lewensvatbaar te maak, onder andere die toevoeging van buigsame montering. Hierdie artikel ondersoek en bespreek die effek wat die toevoeging van buigsame montering op die herkonfigureerbare paradigma het en stel oplossings vir probleme wat inherent aan HVS en die toevoeging van buigsame montering is, voor.

\section{INTRODUCTION}

The modern manufacturing industry experiences frequent and unpredictable changes in the marketplace that have driven the development of agile manufacturing systems [1]. There has been a movement in research towards the responsiveness and practical implementation of agile mass production systems, starting with the introduction of the reconfigurable manufacturing system (RMS) [2].

Since the introduction of practical agile systems, there has been intensive research into enabling technologies and different forms or adaptations of the reconfigurable manufacturing system. Recent research has been done to accelerate the reconfiguration process [1] to allow an RMS to make more frequent changes and thus become more agile [3]. The accelerated RMS does not take as long to reconfigure, which means less downtime. Shorter production runs are thus needed to recoup the losses in production time during a reconfiguration.

Traditionally, some manufacturing systems have used reconfigurable fixturing, fixture redesigns, or modular fixtures to introduce some flexibility into an otherwise traditional mass-production manufacturing system. It is possible for this concept to be extended to the RMS paradigm, along with its own inherent control complications.

This paper is derived from a section of $\mathrm{PhD}$ research currently being undertaken at the University of KwaZulu-Natal, and aims to postulate a manufacturing system that can reduce the penalty of change (POC) suffered by the system, in order effectively to increase its practical flexibility. The goal of the overarching research is to develop a management system (which uses artificial intelligence) for a dynamic Manufacturing Execution System (MES). The system is intended to control a specific form of advanced manufacturing system (AMS). The particular AMS is introduced in this paper, and the 
particular improvements that are required are discussed and the challenges identified (see sections 5 and 3.2). The goal of this paper is to define the manufacturing system that is most suitable for the future market of mass customisation manufacturing (MCM), and to identify the areas that need work to make the proposed system more plausible.

The manufacturing system proposed in this paper is an amalgamation of the paradigms of reconfigurable manufacturing and flexible fixture-based manufacturing. The proposed system has the primary goal of gaining agility over previous systems while not sacrificing productivity. The proposed manufacturing system aims to realise this goal by reducing the time needed to perform a reconfiguration, and by decreasing the debugging and improvement times during manufacturing, making a reconfiguration operation a more profitable course of action. This paper shows how the use of flexible control, artificial intelligence, and automated flexible fixturing can decrease the POC, thus improving the flexibility of the system without sacrificing productivity.

\section{RECONFIGURABLE MANUFACTURING SYSTEMS}

The reconfigurable manufacturing system is a production system paradigm that lies between the traditional dedicated manufacturing system and the newer paradigm of the flexible manufacturing system (FMS), in both its flexibility and its potential production throughput [4]. RMSs aim rapidly to meet the demands of a dynamic, customer-driven market, allowing for effective mass customisation manufacturing (MCM). This area of manufacturing technology has been investigated intensively since its formalisation at the University of Michigan [2]. The RMS paradigm relies on six key characteristics to maintain flexibility without sacrificing throughput: modularity, integrability, diagnosability, convertibility, customisation, and scalability. The key characteristics have been discussed in detail in previous papers $[1,2,4]$.

\subsection{Reconfigurability in RMSs}

Reconfigurability in an industrial manufacturing environment is defined by Gumasta et al. [5] as being "the ability to repeatedly change and rearrange the components of a system in a costeffective way". An RMS is one designed to conduct a fast change of structure or layout of machine hardware and software at a machine and factory level [6]. In other words, an RMS is a manufacturing system specifically designed to be capable of the reconfiguration defined above.

The RMS paradigm relies on many supporting technologies specific to the paradigm to make it feasible. These technologies include reconfigurable machine tools, a rapidly adaptable manufacturing control or execution system, middleware to remove heterogeneity on the factory floor, adaptable manufacturing execution systems, and other systems that facilitate the rapid rampup of production when system-wide changes are undertaken.

\subsection{Control complications}

The inherent flexibility of an RMS brings about challenges in implementation specifically to do with dynamic control and the re-establishment of control after a physical change in the system (a reconfiguration) [1]. The majority of these complications have come about due to the large number of possible combinations of machines and modules on machines on the factory floor (including layout options and tool changes), and due to the inevitable heterogeneity that manifests in a system made up of machines from different vendors - each of which needs to be known by the central control system or manufacturing execution system [3].

The problems stated above have been addressed $[3,7]$ for the current implementations of RMS and similar systems. A level of adaption of the research would be necessary for the additional complications that would be manifest in an implementation of the proposed system (see section $3.2)$.

\subsection{Fixture-Based Manufacturing}

Fixture-based manufacturing systems (FBMS) use fixtures to aid in the production of products and, often, to create additional flexibility [8] in the manufacturing or assembly capabilities of the system (whether or not the fixtures themselves are flexible) [9]. Some flexibility can be afforded to a traditional dedicated manufacturing system through the use of fixtures. This is usually achieved through the variation of fixtures (to hold different parts or to allow fixed machines to operate on 
different faces or areas of a part) and the reprogramming of some machines between high-volume production runs.

\subsection{Traditional fixturing}

Dedicated fixtures are the traditional method of product fixturing, such that a fixture is designed that can constrain a single part (or perhaps a small number of slightly differing parts) for a finite (and determined) number of different production operations [10]. Most traditional fixtures can be changed to adapt to a few different workpieces through limited modularity. However, this modularity does not give the fixtures automated flexibility.

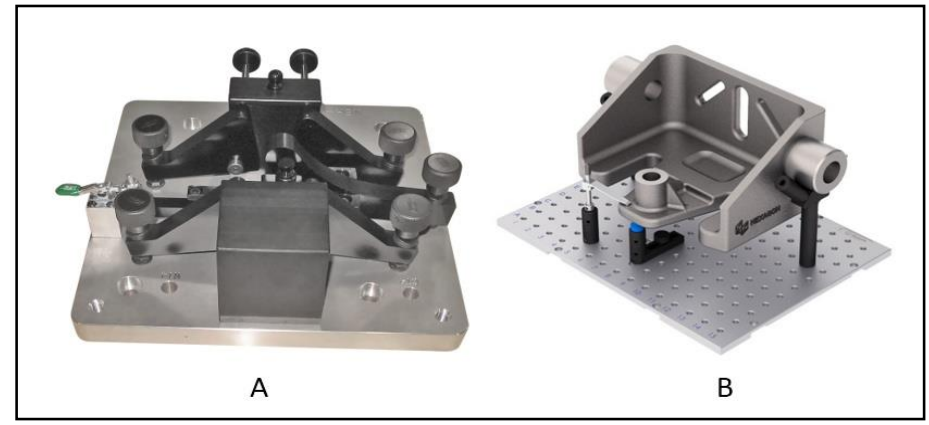

Figure 1: Traditional modular fixture examples [11]

\subsection{Flexible fixturing}

In a reconfigurable or flexible system, using dedicated fixtures increases both the cost and time needed to complete an effective changeover between manufacturing periods (where different products are being made). Previous research has found that using a flexible fixture system aids flexibility and unit production cost when a flexible or reconfigurable production system is in place [11]. It is not always clear how much fixture flexibility is economical and, in some cases, multiple different flexible fixture designs may be available to the manufacturing system, each with different types and degrees of flexibility. Modularity and inherent flexibility in the fixtures aid the production system in dealing with an unpredictable market [12]. It should be clear that the time needed to reconfigure a flexible fixture would be less than the time required to create a fixture from scratch, or to adapt a fixture that was not designed to be flexible to a new product. Part A of Figure 2 below shows a design for a flexible fixturing system under development at UKZN [11].

Robotics can also be used in place of traditional fixtures (or other types of flexible fixturing techniques) in the form of a robotic fixtureless assembly, which replaces traditional fixtures with industrial robotic manipulators that work collaboratively to constrain a workpiece. See part B in Figure 2 below [13].

The control decisions for the formation of different configurations of a fixture in a flexible system can become complex, especially when combined with the rest of the possible configurations of the system. This has also been investigated in detail in previous research [13].

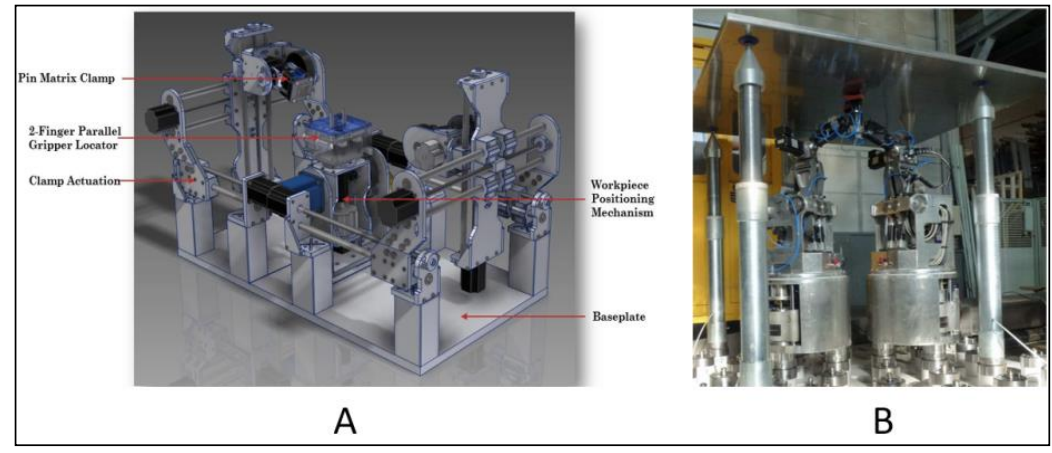

Figure 2: Reconfigurable fixture (A) and collaborative fixture (B) 


\subsection{Production control in systems with flexible fixturing}

Research has been conducted into the planning of the fixture system for reconfigurable systems and fixtures [13]. This research has focused on how the reconfigurability of fixtures affects the planning of the fixture configurations, and how they affect the overall production plans. From a control standpoint, a fixture can be seen as just another part needed for an assembly process, or a piece of raw material needed for a manufacturing process. Flexible fixtures can be used by the control system as long as the control system is aware of what inherent flexibility is contained in the fixture - that is, to what degree the fixture is reconfigurable. In advanced systems, the fixture may be able to adapt on instruction by the system's central control, which negates the usual need to request new, modified fixtures from an inventory. The control system can store, or work out, the possible configurations of the flexible fixtures as a virtual inventory.

\section{THE ADVANCED AMALGAMATED AGILE MANUFACTURING SYSTEM}

Although flexible fixturing and the RMS paradigm have been considered in detail, the two have not been considered as a combined system - even though the addition has many benefits. A system is proposed that actively accounts for a flexible fixturing system as part of the supply chain of the reconfigurable manufacturing system. This proposed system aids flexibility and agility by allowing a faster turnaround time between production periods with differing products. Although this flexibility is expected in an RMS, actively accounting for the flexible fixtures from a design and control point of view allows the flexibility to be more feasible. This system is proposed as the advanced amalgamated agile manufacturing system (AAAMS), an active consideration of flexible fixturing as part of the RMS paradigm. The proposed system fits into the productivity-flexibility graph, shown in Figure 3 and discussed below the figure.

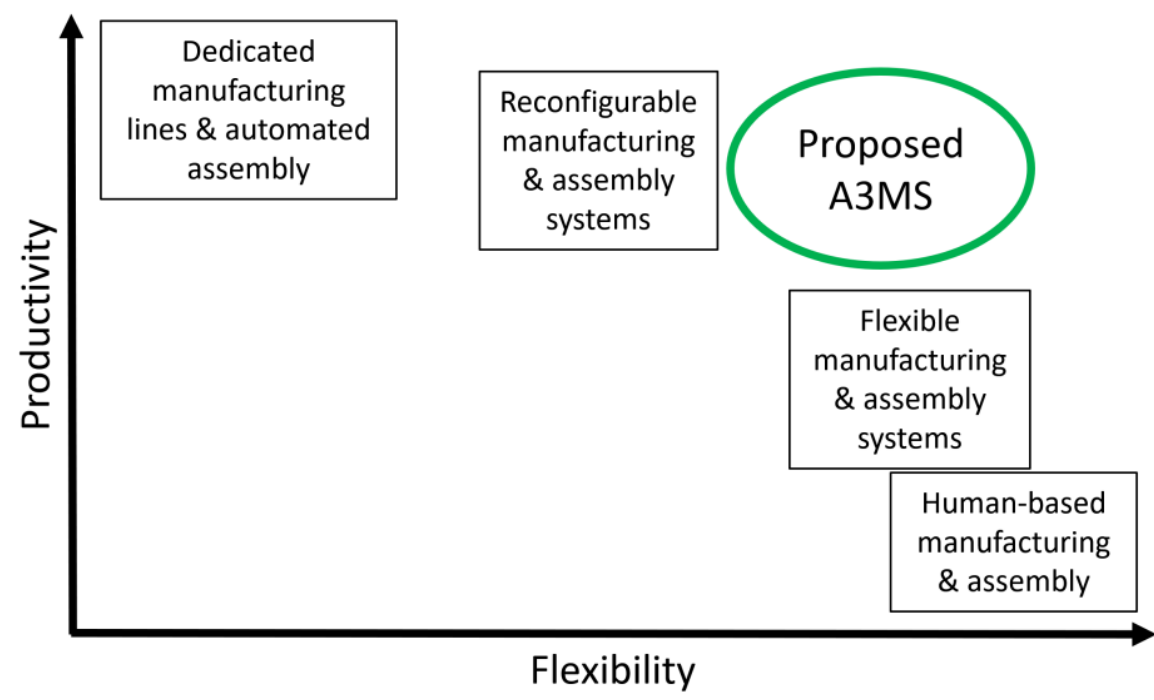

Figure 3: The position of the proposed system compared with existing systems

The major advantage of flexible fixturing is that it can increase the flexibility of a manufacturing system with little or no impact on the productivity of that system. An RMS has traditionally aimed for high throughput - rivalling, but not outperforming, a dedicated system during production runs - while flexibility is handled during reconfigurations. An FMS has permanent flexibility, often using exclusively Computer Numerical Control (CNC) machines, and thus has lower throughput/productivity, but vast flexibility. The most flexible systems are those that rely on skilled workers. These workers can be envisioned as 'endlessly reconfigurable' because they can be trained in many different tasks; but in most cases they will not out-produce an automated line.

The AAAMS aims to challenge the flexibility of an FMS through the addition of highly flexible fixturing techniques and software adaptions, without reducing the throughput of the traditional RMS. It could even be argued that, over many production runs, the addition of flexible fixturing would actually 
improve the productivity, compared with an RMS, by speeding up the transitions between phases of production (the reconfiguration process).

\subsection{Reducing the penalty of change in the AAAMS}

While the concept of flexibility may be easy to describe in rhetoric or discussion, it needs to be defined mathematically in order for definitive decisions to be made. The penalty of change (POC) as a measurement is generic, with the ability to describe multiple types of flexibility; it takes into account economic and technical terms, making it a convenient method for making an estimation of the agility of a system [14]. While there are multiple formulae for the POC, all make use of, and have a comparable effect from, the same set of variables. The example from Mourtzis et al. [14] is used here. It shows that there are a few ways of reducing the POC:

- $\quad$ Reducing the number of changes required in an operation $(D)$

- $\quad$ Reducing the penalty of each, or any one, of the necessary changes $(\operatorname{Pn}(X))$

- $\quad$ Reducing the probability that a change will be needed $(\operatorname{Pn}(X))$

In a well-defined case, the probability that a change will be needed collapses to 1 or 0 , as uncertainty is removed and the POC formula simplifies to a summation of the penalties of each change in the operation. The penalty that any change produces thus becomes dependent only on the number of changes necessary to complete a system change and the penalty of each of those changes.

The POC can be measured as a monetary sum of the lost potential production time and the actual cost of undergoing the change itself. The cost of lost potential production time may be very difficult to define in a system that is built to be used in an MCM role, as the profitability of a system may vary depending on the particular product being produced; but a baseline number can be used, and as long as that number is both conservative and consistent, the calculations should produce valid and defensible results - that is, quicker changes (less lost production time) are beneficial and show better flexibility/agility. The same applies to any labour cost needed for a change, so that the quicker a change is, the less the labour will cost. The inherent cost of change can be well-defined because, if any additional equipment is needed, it has a defined cost. Thus a system can be made more agile by:

- $\quad$ reducing the inherent cost of a change through designing machines to be flexible from the outset, so that changes are inexpensive;

- $\quad$ reducing the inherent cost of new jigs and fixtures through the use of highly flexible fixturing techniques;

$0 \quad$ this will also reduce the time needed for a change because new jigs and fixtures will not need to be ordered;

- $\quad$ increasing the flexibility of machines within the system to reduce the time needed to conduct a change;

- $\quad$ designing a system that facilitates easy machine movement, thus reducing the inherent cost of movement and the time needed for a change;

- $\quad$ reducing or eliminating the need for labour during the change (this is a major focus of the enveloping research);

- $\quad$ reducing the need for offline troubleshooting of the system after a change.

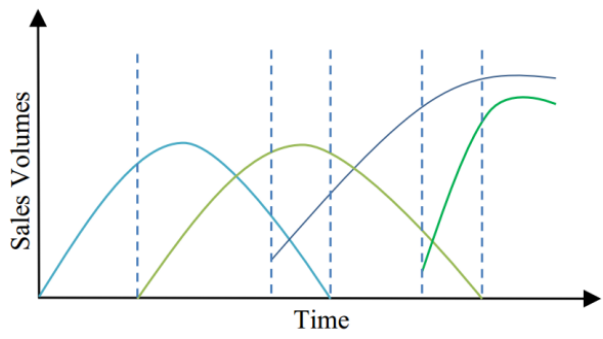

- Product 1 - Generation 1

- Product 2 - Generation 1

- Product 1 - Generation 2

- Product 2 - Generation 2

Figure 4: Cyclic Nature of Sales Volumes of Products/Generations Over Time (see online version for colour) 


\subsection{Problems \& challenges in the AAAMS paradigm}

The particular challenges faced by AAAMSs are similar to those of an RMS, with the challenges being exacerbated in many cases. The particular areas that cause additional complexities for the control structure are task scheduling, factory floor layouts, the re-establishment of control after a reconfiguration, potential missed opportunities or underperformance, and how the system reacts to disturbances and perturbations. The enveloping research has focused on the control needed to ensure optimal operation of an AAAMS, rather than on the supporting hardware. Thus the challenges discussed here are focused on those that affect the control structure of the system.

\subsection{Task scheduling}

The scheduling of machine operations and materials handling routes has a profound effect on the operational efficiency of an advanced manufacturing system [15], and can be described in the form of manufacturing flow control [16]. Flow control in a manufacturing system can be decomposed into a broad resource allocation problem, with multiple types of families or jobs, each of which requires one manufacturing resource that is capable of adapting to the needs of the jobs or families [17]. In an agile system, manufacturing flow control can be seen as the balancing of two opposing forces in the production system; the variability produced by the arrival of different job types or part families; and the desire for a stabilisation of work-in-progress in the system [17].

The setup time of a machine of any one entity in an advanced manufacturing system is, in general, not negligible, and should not be considered such in reconfigurable $[17,18]$ or flexible systems [19]. Other research has found that systems can have all of their task scheduling needs processed by the traditional Petri-Net approach, but optimised by artificial intelligence [20].

This area of research is well-studied; but for the purpose of the proposed AAAMS, a dynamic system for the scheduling of tasks and control of manufacturing flow is required. The systems proposed by Walker and Bright [17] or by Li and Xie [20] are both candidate solutions to the problem that lends some plausibility to the paradigm by addressing an obvious complication over traditional manufacturing systems from the outset.

\subsection{Ideal layouts \& materials handling}

The layout of a system, especially one that is reconfigurable in its physical layout, is highly important to the production efficiency of the system. The variation of layout goes hand-in-hand with the materials handling system, and thus the materials handling considerations must affect the layout design. There has been significant research into the layout of a system, with configurations for DMSs at an advanced stage [21, 22]. New research has been conducted on specific flexible, dynamic, and reconfigurable systems [23-25]. Much of the earlier research on dedicated or static production systems has influenced the layout research of the newer agile systems, with only very specific modifications needed to make them applicable to the new paradigms. Research by Padayachee et al. [26] has investigated specific layout and materials handling for the case of customer-driven reconfigurable manufacturing, as implemented in an AAAMS. This research shows that an RMS needs particular supporting technology and a layout that facilitates reconfiguration in order to be effective. The system will not be able quickly and cost-effectively to change its structure unless it is designed for this transition from the outset. The designer of an RMS layout strategy needs to preempt the system evolution so that a particular manufacturing configuration can easily, costeffectively, and smoothly transition into a new configuration [26]. Research has been conducted into the prediction of ideal layouts and materials handling approaches that can be used in reconfigurable systems, with the research focused on the best layout in each particular production cycle [26]. This research has added to the existing body of literature by taking into account upcoming production periods in order to minimise factory downtime and machine movement while still allowing for maximum production capacity.

As mentioned above, the materials handling cost is an important part of any system. Work by Saghafian and Jokar [22] has defined the extra cost of materials handling due to sub-optimal cellular layouts. The research shows that the more production entities there are outside of their ideal placement, the more materials handling costs will increase. This may seem like an obvious conclusion, but the importance of the cost formula is that it shows that the materials handling cost goes up at a linearly summed rate rather than a multiplied or exponential rate. The research by Padayachee and Bright [26] showed that this cost can be offset in a highly dynamic system by the 
reduction of moving costs. The AAAMS will be at least as dynamic in nature, thanks to its increased flexibility, as with the RMS that was the focus of Padayachee and Bright's research [26]. This means that the ideal placement must follow the guidelines outlined there, rather than other traditional cell optimisation methods. This means that layout in a system as dynamic as the AAAMS is less important than true flexibility, but constant work should be done by Al to make sure that a balance is found between moving cost and handling efficiency.

\subsection{Re-establishment of control after a system reconfiguration}

The re-establishment of control of the system after a full reconfiguration is a problem carried through from the RMS paradigm; it is a problem of state detection, efficiency, and heterogeneity. In order to be flexible or agile, a system must necessarily be able to change between production states quickly. Previously, a bottleneck occurred when the system was placed in its new state but had to have the software on all the machine controllers reconfigured. This issue was addressed in previous research, which proposed a system that handles the re-establishment of control in an RMS $[1,3]$.

In addition to the papers cited above, research has been done on specific middleware systems that do not address the problem of detecting the factory floor state to make decisions, but that create a better means of homogeneous communication with entities controlled by heterogeneous controllers [27, 28]. These software systems can be useful when some other method is used to monitor the physical state of the entities on the factory floor.

The AAAMS will undergo more production phase changes in a given time than other production techniques (even the RMSs, which the papers cited in this section handled). For this reason, the reestablishment of control with minimal labour, downtime, and errors is even more vital to the successful operation of the system. Part of the research that envelops this paper has been focused on the intelligence behind solving issues on the factory floor without the need for a system shutdown; the research that was done previously on the re-establishment of control shares many common traits with a system that can adapt control in a live system. When large (and physical) system reconfiguration has taken place, the methods previously developed can be used, with a little adaptation, in the AAAMS.

\subsection{Underperformance and opportunities}

Traditional dedicated manufacturing systems usually have a period of optimisation or validation after the beginning of production, in which the production data is analysed and changes are made to boost productivity or solve issues. This validation period may need to span a long period before changes are made to the system [29]. In the event that a shutdown in production is needed in order to increase efficiency, there is a duality between the need for efficiency and the loss in production during the shutdown. In the long production cycles associated with a dedicated mass production system, this often results in the system being shut down to improve performance. Ideas have been put forward for the live-update of dedicated manufacturing systems for dynamic optimisation [18, 30]. The cited research papers only dealt with a fixed physical structure, so the update options are limited to small control modifications. These control modifications can nonetheless still be profitable in many cases [18].

TSeizing market and supply opportunities is not in the realm of possibility for dedicated manufacturing systems, but is rather a core driver of the agile manufacturing paradigms (FMS, RMS, and the proposed AAAMS).

$\mathrm{n}$ the highly dynamic paradigms of RMS and the proposed AAAMS, the job cycles are, by the design of MCM, often too short for any initial optimisation or verification. The period needed to validate a dedicated line may span most of an entire production period for an RMS or the proposed AAAMS. In the RMS paradigm, if a shutdown is needed to increase efficiency, the duality often lies in favour of continuing production with lower efficiency, rather than making changes and having downtime.

The AAAMS aims to include the ability to address underperformance without the need for a shutdown, thereby improving the overall agility and efficiency of the system. This ability will allow for a system that operates closer to its optimal productivity without the need for frequent shutdowns for optimisation improvements. 
Opportunities in the paradigm of AAAMS may arise as market opportunities (as in the RMS paradigm [6]) that the system can seize more quickly than any dedicated manufacturing system, but more cost-effectively than a full FMS. Because of the nature and agility of the AAAMS, it is able to take advantage of market changes through the rapid adaptation of the manufacturing process. Missing an opportunity would constitute a type of system underperformance, and adding flexibility helps to prevent this event.

With the high flexibility of the AAAMS, additional opportunities can arise during a production process; a bottleneck may have less effect than predicted during the planning. For instance: extra fixtures/feeder parts/raw materials may become available; the quality may be higher than required, or tool wear may be lower than expected, allowing the manufacturing process to be accelerated; or additional (previously limiting) manufacturing entities may become available to the system (for instance, an extra milling machine, where the first was a bottleneck to the system and a second has become available and can be added to a parallel arm of the production line). The opportunities listed above can be recognised in any production line, but most systems do not have the flexibility to exploit the favourable circumstances. The AAAMS is designed to handle these opportunities through rapid live adjustments to the control of the system, aided by the high level of flexibility (see section 5).

\subsection{Perturbations \& system disturbances}

All systems can be, and usually are, affected by perturbations and disturbances to system operation $[31,32]$. While the existence of the perturbations and disturbances is not unique to the RMS paradigm or to the concept of the AAAMS, they have a greater effect on production because of shorter production cycles for which these agile, reconfigurable systems are designed. Because RMSs and the proposed AAAMS paradigm aim for high output, any system disturbance can cause large production and profitability losses compared with an Numeric Control-based FMS, one which heavily makes use of reprogrammable CNC machines and robots. The disturbances are also much more likely (compared with dedicated mass manufacturing) because of the non-steady-state nature of the production [32]. The cited paper [32] has investigated the control architecture for a system able to handle "out-of-the-ordinary events" in a traditional RMS, using an expert system to handle errors and perturbations. Dedicated lines can go months with no production change, and therefore they are generally more reliable and subject to fewer effective perturbations and disturbances, because of their predictability and the validation/optimisation period afforded them. Thus the problem of perturbations and disturbances has a particular effect on reconfigurable manufacturing - an effect that impinges on the practicality of RMS that new technology in the additional flexibility and control in the AAAMS aims to alleviate (see section 5).

The primary perturbations that need to be handled in an AAAMS are: a shortage of raw materials, feeder parts, or fixtures; the breakdown or underperformance of entities on the factory floor; lower than expected quality; and excessive tool wear [32]. Each of these situations can cause errors in the manufacturing control. If the control system cannot adapt to the perturbations by changing the control system itself, then the only option will be to halt production and to reprogram or manually adapt the control system to suit the new physical parameters, or to fix the physical issue (for example, tool wear) immediately. The lack of a mature, adaptable manufacturing execution system remains a challenge in the implementation of advanced RMSs, leading to slower overall reconfiguration times and the reduction of feasibility because of potential excessive downtime during production runs.

To re-iterate, RMSs are more challenged by the problem of perturbations than dedicated manufacturing systems (DMSs) because they do not have a lengthy optimisation period. DMSs run production cycles for long periods of time, which means that they can make up the long optimisation and setup time through high production rates and long production periods. Reconfigurable manufacturing techniques, by definition, need to be agile, and will thus run with shorter production periods, leaving less time for profitable optimisation in the traditional sense. Advanced adaptable control techniques have been researched (see section 5.1.1), but little has been done thus far to manage these adaptable techniques. 
This modelling experiment compares the POC and production output for a traditional RMS and FMS with those of the proposed AAAMS under a few production settings and disturbances.

\subsection{Example study}

With the well-planned six-period manufacturing problem, as documented in work by Padayachee and Bright [39] on dynamic cellular manufacturing systems (DCMSs), the concept of the AAAMS is demonstrated. DCMSs are another advanced evolution of the RMS, with a focus on cellular layouts in the RMS. DCMSs can also incorporate the concept of flexible fixturing and the associated control to become AAAMSs, which can lead to distinct advantages. The research focused on the most efficient way to lay out a manufacturing system when changes in the system are expected, while the cost associated with re-fixturing and updating control was not considered because it was not affected by the results of the research. Table 1, adapted from Padayachee and Bright [39], shows the part requirements over the six year-long periods:

Table 1: Part volumes for each period [39]

\begin{tabular}{|l|l|l|l|l|l|l|l|}
\hline \multirow{2}{*}{ Part number } & \multirow{2}{*}{ Cycle time (mins) } & \multicolumn{5}{l|}{ Part volumes } \\
\cline { 3 - 7 } & & $Y 1$ & $Y 2$ & $Y 3$ & $Y 4$ & $Y 5$ & $Y 6$ \\
\hline 1 & 36 & 4000 & 3500 & 2000 & 0 & 0 & 0 \\
\hline 2 & 38 & 4000 & 3500 & 2000 & 0 & 0 & 0 \\
\hline 3 & 30 & 0 & 6000 & 9000 & 6400 & 3000 & 0 \\
\hline 4 & 31 & 8000 & 7000 & 4000 & 0 & 0 & 0 \\
\hline 5 & 41 & 0 & 0 & 0 & 1500 & 3000 & 5000 \\
\hline 6 & 43 & 4000 & 3500 & 2000 & 0 & 0 & 0 \\
\hline 7 & 37 & 4000 & 3500 & 2000 & 0 & 0 & 0 \\
\hline 8 & 33 & 0 & 0 & 0 & 3000 & 6000 & 10000 \\
\hline 9 & 31 & 0 & 6000 & 9000 & 6400 & 3000 & 0 \\
\hline 10 & 34 & 0 & 3000 & 4500 & 4700 & 4500 & 5000 \\
\hline 11 & 44 & 4000 & 3500 & 2000 & 0 & 0 & 0 \\
\hline 12 & 45 & 0 & 0 & 0 & 1500 & 3000 & 5000 \\
\hline 13 & 45 & 0 & 3000 & 4500 & 3200 & 1500 & 0 \\
\hline 14 & 36 & 8000 & 7000 & 4000 & 0 & 0 & 0 \\
\hline 15 & 42 & 0 & 0 & 0 & 1500 & 3000 & 5000 \\
\hline 16 & 41 & 4000 & 3500 & 2000 & 0 & 0 & 0 \\
\hline 17 & 34 & 0 & 0 & 0 & 3000 & 6000 & 10000 \\
\hline 18 & 37 & 0 & 3000 & 4500 & 4700 & 4500 & 5000 \\
\hline 19 & 41 & 0 & 3000 & 4500 & 3200 & 1500 & 0 \\
\hline 20 & 50 & 0 & 3000 & 4500 & 3200 & 1500 & 0 \\
\hline
\end{tabular}

The research by Padayachee and Bright [39] shows that the parts below can be divided into two separate part families, capable of being manufactured in a two-cell system, assuming that the parts within a family can be fixtured using one reconfigurable fixture, which, given the research presented before (see 2.5), is likely.

\subsection{AAAMS vs traditional RMS}

This section discusses and compares conceptually the solutions of a traditional RMS, using nonflexible fixturing, and the AAAMS.

\subsubsection{Traditional fixturing with cellular RMS}

If flexible fixturing is not used, the following gives an estimation of the minimum number of fixtures needed, considering the cellular layout shown in the referenced research. Each of the parts would need its own unique fixture, based on the maximum number that part would need over its production runs, and assuming 250 eight-hour working days in a production period of one year. Twenty unique 
types of fixtures would be required to jig the different parts, with about 116 fixtures (four to eight per part, depending on the part). Storage is limited in this case study, so external storage is an expense to be considered. The highest number of fixtures will be used in periods $Y 2$ and $Y 3$; thus during other periods with lower demands, storage needs will be high, although there will be a need for a large amount of storage at all times.

\subsubsection{Cellular AAAMS with flexible fixturing}

When flexible fixturing is used, with the two families of related parts, only two fixturing solutions at most would be required, and seven fixtures of each type at most will be required (maximum number of machines in a cell, so maximum number of parts in progress, plus one for preparation). In this case, there will be no need for re-fixturing between production periods and no need for possibly costly external storage.

\subsection{Results}

It should be clear that the number of fixtures needed to achieve the requirements of this case system is far lower when using the AAAMS. While not all the attributes of the AAAMS - in particular, the control advantages - are shown here, the fixturing advantages are made visible. When considering the cost of the flexible fixturing, it is evident that a flexible fixture costs more than a traditional fixture; but this cost is well offset by the number of fixtures required to achieve the needs with traditional fixturing. This cost advantage is pushed further by space savings.

\section{DISCUSSION AND CONCLUSION}

The problems and challenges introduced above (section 3.2) are to be addressed in future research on the subject, which will aim to solve these problems through the adaption of control. It was surmised that control adaption is best achieved through the management of an existing technology, known as the adaptable MES, or AMES, which allows the execution of tasks in a manufacturing system to be changed more easily than in a traditional MES. The case study above shows that the inclusion of flexible fixturing to create the AAAMS increases the profitability of the system. The presented study does not have a great deal of control complexity and has reasonably long production periods. It is thus well-suited as a conceptual presentation, but does not outline the challenges of adding the control complexities of the AAAMS. Further research is discussed below.

\subsection{Discussion of further required research}

There are two particular areas of research that need focus to make the AAAMS practical from a control perspective. These are discussed below. While the inclusion of flexible fixturing will improve the cost-effectiveness of a dynamic manufacturing system, as shown in section 4 , that case study did not consider the complexities added by this inclusion. These complexities are discussed throughout the paper.

\subsubsection{The adaptable MES}

A manufacturing execution system (MES) is a factory control level that lies directly below the business control level [32] - that is, software such as ERP, MRP, MRPII, and other similar packages. The MES is more involved in the control of the manufacturing system, but makes no direct decisions. The MES typically receives manufacturing instructions from an ERP system or directly from an expert operator. It can be viewed as the part of the factory control system that outlines the job of each individual control agent, but which does not have any direct interactions with sensors or actuators. MESs are not a technology unique to RMSs or other adaptable or flexible manufacturing systems [33], but research has been done into MESs which are built to be adaptable from the outset [32]. Although there has been research into a reconfigurable $M E S$, the research offers reconfiguration time frames on the scale of months [33], so that the MES is only reconfigured every time there is a large change in the process.

Rolón and Martinez [33] presented a detailed paper on autonomic MESs that may serve as the base for any dynamic MES design. The paper covers the development of the adaptive MES for use in the general production system. The paper does not sufficiently address the management of the system, but provides an informative framework and shows the feasibility of a dynamic/autonomic MES.

The primary goal of the adaptable MES in current research is to speed up the re-establishment of control after a system change (in particular, a reconfiguration operation in an RMS), or when a 
change is needed, according to a human user. This research investigates using such a system for the optimisation of production when the system experiences a perturbation or disturbance, detects an opportunity, or is performing below expectation (as discussed in sections $3.6 \& 3.7$ ).

\subsubsection{Al management of an adaptable MES}

Significant research has been conducted into the use of distributed intelligence to allow for selfadaptive control in a reconfigurable manufacturing environment [35]. This research focused on the use of holonic methods and a knowledge-based system to update the control of a system to suit the manufacturing environment autonomously. It particularly focused on seamless small-scale changes in the production control to deal with product demand and production system changes (as discussed in 3.7). Other systems have also been investigated that target only modular production systems (MPSs), which are a particular type of RMS [35]. Research from the Institute of Industrial Technologies and Automation in Italy has investigated the implementation of a self-adaptive control system in a specific type of RMS [35]. This research shows that the live and rapid update of a factory's control system is possible, and can thus be used to deal with perturbations from both endogenous and exogenous factors. The cited research was focused on rapid and frequent changes in customer demands, and thus did not include advanced Al for decision-making.

Further research is needed to make rapid control decisions to speed up the response of the system to any required change in the situation or market environment. Creating a system to make decisions on the live updating of a factory floor's MES could prove to make a cellular, fixture-based, MES more profitable by taking advantage of opportunities and minimising the effects of breakdowns in a highly automated system.

Research is underway at UKZN to develop this intelligence through a combination artificial neural network (ANN) (trained by a genetic algorithm (GA)) and fuzzy logic expert system (FLES). The ANN will be developed to access factory floor situation information and market parameters, and will produce an output to be interpreted by the FLES. The reaction needs to be automated, so that no human interaction or planning is needed for the AAAMS to adapt itself, without a significant break in production, to handle the situation.

\subsection{Conclusions}

The proposed AAAMS is not in a paradigm of its own, but is rather a modified RMS. Although there are significant challenges (see section 3.2) to the implementation of the AAAMS, it shows genuine promise as a variation of the traditional RMS. The case study presented in section 4 shows that profitability can be improved through the use of an AAAMS, even in this limited-complexity case.

This research has aimed to identify the challenges facing the implementation of a new type of advanced manufacturing system - the AAAMS. The particular challenges faced by the AAAMS have been discussed and decomposed, and it has been shown that each of the challenges can be met through the limited adaption of previous research, and by conducting new, novel research. There is a particular need for research into Al management of an adaptable MES (see sections $3.6 \& 3.7$ ). The development of this system is the goal of the enveloping research.

The AAAMS is more focused on flexibility and the ability to adapt to small changes quickly and efficiently. The additional research needed to make the AAAMS a plausible system (see section 5) is all within the reach of today's technology, and should show that the AAAMS can match, or better, an RMS for output, and approach the flexibility of some traditional FMSs.

\section{REFERENCES}

[1] McLean, R.R.P., Padayachee, J. and Bright, G. 2015. A thin, hardware-supported middleware management system for reconfigurable manufacturing systems, South African Journal of Industrial Engineering, 26, pp. 207-223.

[2] Koren, Y., Heisel, U., Jovane, F., Moriwaki, T., Pritschow, G., Ulsoy, G. and Van Brussel, H., 1999. Reconfigurable manufacturing systems, Annals of the CIRP, 48, pp. 527-540.

[3] McLean, R., Padayachee, J. and Bright, G. 2016. A hardware supported middleware and autonomous software update system for reconfiguration management in the reconfigurable manufacturing systems paradigm. Presented at the International Conference on Competitive Manufacturing, Stellenbosch, South Africa. 
[4] Koren, Y. and Shpitalni, M. 2010. Design of reconfigurable manufacturing systems, Journal of Manufacturing Systems, 29, pp. 130-141.

[5] Gumasta, K., Gupta, S., Benyoucef, L. and Tiwari, M.K. 2011. Developing a reconfigurability index using multi-attribute utility theory, International Journal of Production Research, 49, pp. 1669-1683.

[6] Malhotra, V., Raj, T. and Arora, A. 2010. Excellent techniques of manufacturing systems: RMS and FMS, International Journal of Engineering Science and Technology, 2, pp. 137-142.

[7] McLean, R., Padayachee, J. and Bright, G. 2015. A middleware management system with supporting holonic modules for reconfigurable management system, International Journal of Mechanical, Aerospace, Industrial, Mechatronic and Manufacturing Engineering, 9, pp. 1552-1558.

[8] Wang, H., Rong, Y., Li, H., Shaun, P., 2010. Computer aided fixture design: Recent research and trends, Computer-Aided Design, 42, pp. 1085-1094.

[9] Sequeira, M.A. and Basson, A.H. 2009. Case study of a fixture-based reconfigurable assembly system, in IEEE International Symposium on Assembly and Manufacturing, Suwon, Korea, pp. 387-392.

[10] Rong, Y.K. and Li, X.C. 1997. Locating method analysis based rapid fixture configuration design. Presented at the 6th International Conference on Emerging Technologies and Factory Automation Proceedings, Los Angeles, USA.

[11] Illidge, A., Walker, A. and Bright, G. 2015. An intelligent locator inventory to accommodate mass customization in an automated flexible fixture system. Presented at the Robotics and Mechatronics Conference of South Africa, Port Elizabeth, South Africa.

[12] Bi, Z.M. and Zhang, W.J. 2001. Flexible fixture design and automation: Review, issues and future directions, International Journal on Design and Automation, 39, pp. 2867-2894.

[13] Zieliński, C., Kazprzak, W., Kornuta, T., Szynkiewicz, W., Trojanek, P., Walęcki, M. Winiarski, T. and Zielińska, T., 2013. Control and programming of a multi-robot-based reconfigurable fixture, Industrial Robot: An International Journal, 40, pp. 329-336.

[14] Mourtzis, D., Alexopoulous, K. and Chryssolouris, G. 2012. Flexibility consideration in the design of manufacturing systems: An industrial case study, CIRP Journal of Manufacturing Science and Technology, 5, pp. 276-283.

[15] Crama, Y. 1997. Combinatorial optimisation models for production scheduling in automated manufacturing systems, European Journal of Operational Research, 99, pp. 136-153.

[16] Herrmann, J.W. 2007. The legacy of Taylor, Gantt and Johnson: How to improve production scheduling, The Institute for Systems Research, James Clark School of Engineering, Washington, DC, USA.

[17] Walker, A.J. and Bright, G. 2013. Manufacturing flow control using biased minimum feedback. Presented at the IFAC Conference on Manufacturing Modelling, Management, and Control, St Petersburg, Russia.

[18] Sharifina, A., Caramanis, M. and Gershwin, S.B. 1991. Dynamic setup scheduling and flow control in manufacturing systems, Discrete Event Dynamic Systems, 1, 1-23.

[19] Badr, I. 2008. An agent-based scheduling framework for flexible manufacturing systems, World Academy of Science, Engineering and Technology, 40, 363-369.

[20] $\mathrm{Li}, \mathrm{A}$. and Xie, N. 2006. A robust scheduling for reconfigurable manufacturing system using petri nets and genetic algorithm. Presented at the Proceedings of the 6th World Congress on Intelligent Control and Automation, Dalian, China.

[21] Ariafar, S. and Ismail, N. 2009. An improved algorithm for layout design in cellular manufacturing systems, Journal of Manufacturing Systems, 28, pp. 132-139.

[22] Saghafian, S. and Jokar, M.R.A. 2009 Integrative cell formation and layout design in cellular manufacturing systems, Journal of Industrial and Systems Engineering, 3, pp. 97-115.

[23] Hasan, F., Jain, P.K. and Kumar, D. 2014. Performance issues in reconfigurable manufacturing systems, in DAAAM International Scientific Book 2014. Vienna, Austria: DAAAM International, pp. 295-310.

[24] Kumar, R.M.S., Asokan, P. and Kumanan, S. 2008. Design of loop layout in flexible manufacturing system using non-traditional optimization technique, International Journal of Advanced Manufacturing Technology 38, pp. 594-599.

[25] Golmohammadi, A.M., Tavakkoli-Moghaddam, R., Jolai, F. and Golmohammadi, A.H. 2014. Concurrent cell formation and layout design using a genetic algorithm under dynamic conditions, UCT Journal of Research in Science, Engineering and Technology, 2, pp. 08-15.

[26] Padayachee, J. and Bright, G. 2014. Synthesis of evolving cells for reconfigurable manufacturing systems. Presented at the 27th International Conference on CADCAM, Robotics and Factories of the Future, London, England.

[27] Roulet-Dubonnet, 0. 2011. Distributed control of flexible manufacturing systems: Implementation of a specialized multi-agent middleware and applications of holonic concepts, PhD, Norwegian University of Science and Technology.

[28] Kavimandan, A. and Gokhale, A. 2008. Automated middleware QoS configuration techniques for distributed real-time and embedded systems, IEEE Real-Time and Embedded Technology and Applications Symposium, pp. 93-102.

[29] Harrison, W.S., Tillbury, D.M. and Yuan, C. 2011. From hardware-in-the-loop to hybrid process simulation: An ontology for the implementation phase of a manufacturing system, IEEE Transactions on Automation Science and Engineering, 9, pp. 96-109.

[30] Li, Y., Chang, Q., Brundage, M.P., Biller, S., Arinez, J. and Xiao, G. 2015. Market demand oriented datadriven modeling for dynamic manufacturing system control, IEEE Transactions on Systems, Manufacturing, and Cybernetics: Systems, 45, pp. 109-121. 
[31] Akella, R. and Kumar, P.R. 1985. Optimal control of production rate in a failure prone manufacturing system, IEEE Transactions on Automatic Control 31, pp. 116-126.

[32] Frizelle, G., McFarlane, D. and Bongaerts, L. 1998. Disturbance measurement in manufacturing production systems, in The Annual Conference of ICIMS-NOE-ASI, Bremen, Germany.

[33] Moyne, J., Korsakas, J., Milas, C., Hobrla, T., Hong, T. Kim, H., Priskorn, J., Sukerkar, K., Wijaya, H., Agarwal, N., Tilbury, D. 2003. A software infrastructure for reconfigurable manufacturing systems, in CIRP 2nd International Conference on Reconfigurable Manufacturing, Ann Arbor, Michigan, USA, pp. 1-8.

[34] Rolon, M. and Martinez, E. 2012. Agent-based modeling and simulation of an autonomic manufacturing execution system, Computers in Industry, 63, pp. 53-78.

[35] Brusaferri, A., Ballarino, A. and Carpanzano, E. 2010. Distributed intelligent automation solutions for self-adaptive manufacturing plants, in IFIP International Federation for Information Processing, Milan, Italy.

[36] Friedrich, J., Scheifele, S., Verl, A. and Lechler, A. 2014. Flexible and modular control and manufacturing system, in CIRP Conference on Intelligent Computation in Manufacturing Engineering, Naples, Italy, pp. 115-120. 